\title{
Causes of blindness in people aged 50 years and over: community-based versus hospital-based study
}

\author{
S.A. Al-Akily, ${ }^{1,2}$ M.A. Bamashmus ${ }^{1,2}$ and K.A. Al-Mohammadi ${ }^{3}$
}

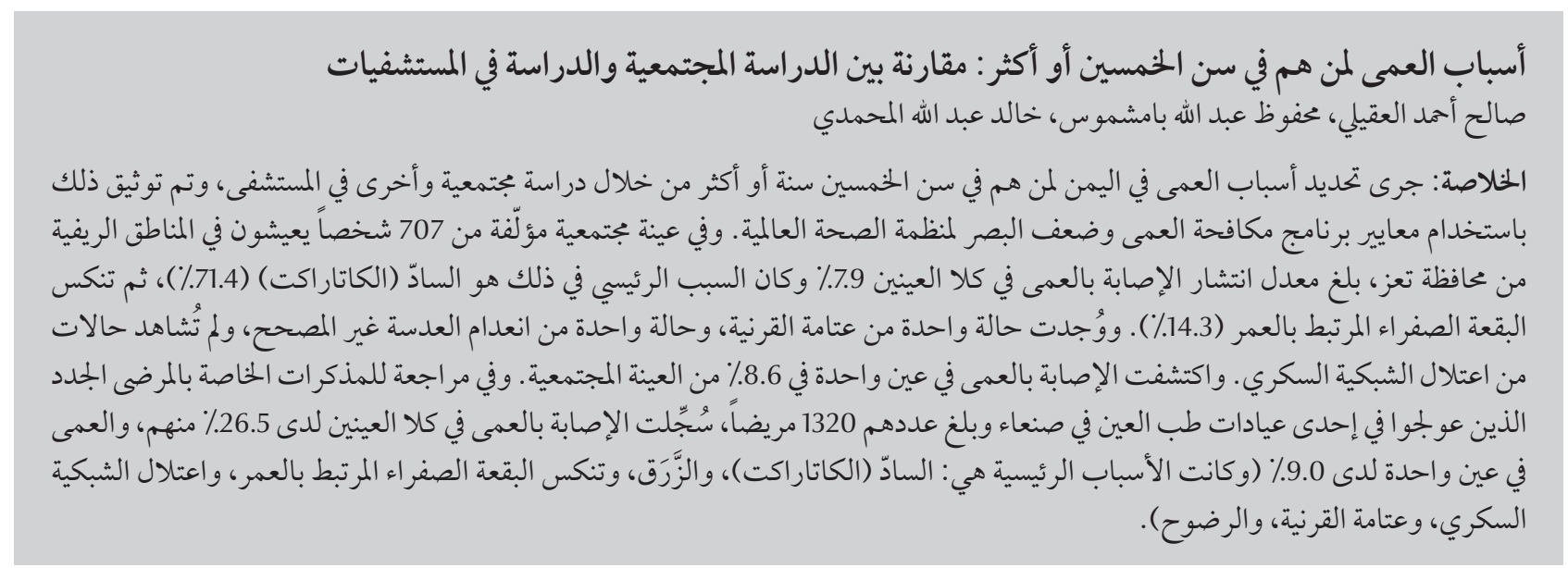

ABSTRACT The causes of blindness in Yemen were determined in people aged 50+ years in both a communityand hospital-based study and documented using WHO/PBL criteria. In the community sample of 707 individuals in a rural area of Taiz governorate the prevalence of bilateral blindness was $7.9 \%$ and the main causes were cataract (71.4\%) and age-related macular degeneration (ARMD) (14.3\%). Corneal opacities and uncorrected aphakia were rare (1 case each) and there were no cases of diabetic retinopathy. Unilateral blindness was found in $8.6 \%$ of the community sample. In a case-notes review of 1320 new patients attending an eye clinic in Sana'a, bilateral blindness was documented in $26.5 \%$ and unilateral blindness in $9.0 \%$ (main causes: cataract, glaucoma, ARMD, diabetic retinopathy, corneal opacities and trauma).

Causes de cécité chez les personnes âgées de 50 ans et plus : étude comparant des données recueillies au sein d'une communauté et en milieu hospitalier

RÉSUMÉ Au Yémen, les causes de cécité chez les sujets âgés de 50 ans et plus ont été déterminées dans le cadre d'une étude réalisée à la fois au sein d'une communauté et en milieu hospitalier. Elles ont ensuite été documentées selon les critères du Programme OMS de Prévention de la cécité. Pour l'échantillon de 707 individus issus d'une région rurale du gouvernorat de Taïz sur lequel portait l'étude communautaire, la prévalence de la cécité bilatérale était de $7,9 \%$, avec pour principales causes la cataracte $(71,4 \%)$ et la dégénérescence maculaire liée à l'âge (14,3\%). Les opacités cornéennes et les aphakies non corrigées se sont révélées rares (un cas pour chaque) et aucun cas de rétinopathie diabétique n'a été recensé. En outre, 8,6 \% de l'échantillon communautaire présentait une cécité unilatérale. Dans le cadre de l'analyse des notes de cas qui portait sur 1320 patients se présentant pour la première fois à une consultation ophtalmologique à Sanaa, une cécité bilatérale a été documentée chez 26,5\% des patients et une cécité unilatérale chez $9 \%$ d'entre eux (principales causes : cataracte, glaucome, dégénérescence maculaire liée à l'âge, rétinopathie diabétique, opacités cornéennes et traumatisme). 


\section{Introduction}

Blindness constitutes a significant public health problem in many countries. The available data suggest that in the year 2002 the estimated number of people with visual impairment globally was in excess of 161 million: 37 million were blind and 124 million had low vision $[1,2]$ The majority live in Asia and Africa. Of the 37 million blind people in the world, it is estimated that approximately half of cases are due to cataract $(47.8 \%)$, with the remainder mainly due to glaucoma (12.3\%), agerelated macular degeneration (ARMD) (8.7\%), corneal opacities (5.1\%) and diabetic retinopathy $(4.8 \%)[1,2]$. Uncorrected refractive error is also a cause of visual impairment and is estimated to affect another 153 million people [2]. Uncorrected refractive errors then become the main cause of low vision and the second cause of blindness [3].

Due to the increasing populations and rising life expectancies blindness is a growing problem worldwide, causing loss of quality of life to the individual and an economic burden on the individual, family and society in general. Yemen is a poor country with a human development index of 0.508 , human poverty index of 38.0, life expectancy of 61.5 years and literacy rate of $54.1 \%$. The family health survey conducted by the Ministry of Health in 2003 revealed that $2.9 \%$ of the population had some kind of self-reported handicap, with visual handicap representing $36 \%$ of the total identified disabled individuals in the country [4]. To our knowledge there are no published communitybased studies on the causes of blindness in Yemen. The available data on the frequency and causes of blindness in Yemen were all obtained from hospital settings $[3,5,6]$. This study therefore aimed to compare the causes of bilateral and unilateral blindness in people aged 50 years and over in both a communityand hospital-based study.

\section{Methods}

\section{Sample}

For the community-based study a total of 707 individuals aged 50+ years were examined in a non-interventional, cross-sectional descriptive population study in Hethran subdistrict of Taiz governorate, which is a peri-urban area $8 \mathrm{~km}$ west of Taiz city. It is divided into 7 villages, which have 43 hamlets and 994 houses with a total population of 5427 individuals, 2798 males (51.6\%) and 2629 females (48.4\%). During July to August 2002 all individuals aged $50+$ years living in the district and who had resided there for $6+$ months were approached in a door-to-door survey. Those who refused to be examined were coded as absentees, then after 3 visits, they were coded as blind or not blind according the reply of his/her family member.

The sample for the hospital-based study was the records of 1320 consecutive new patients aged $50+$ years attending Ibn Al-Haitham eye centre (affiliated to the University of Science and Technology) in the capital city, Sana'a, from January to December 2002.

Verbal consent was taken from all eligible individuals. All records and personal information were kept confidential. Both studies had approval from the local ethics committees.

\section{Data collection}

For the community-based study the individuals were given an eye examination at home by the same consultant ophthalmologist (K.M.).

In the hospital based-study the cases notes of the patients were retrieved and analysed. All patients had been examined by the same consultant ophthalmologist (M.B).

The data collected for both studies included age, sex, chief complaint and complete eye examination. The medical history, family history and ophthalmological evaluation were reviewed and recorded. Visual acuity was measured using the Snellen chart. Eye examination included slitlamp, fundoscopy, retinoscopy and tonometry, as required. Goldmann applanation was used in the hospital and Schiotz tonometer in the community study.

All findings were recorded according to the World Health Organization Programme for the Prevention of Blindness (WHO/PBL) eye examination record (version III) [7]. Unilateral blindness was defined as a corrected visual acuity $3 / 60$ or below in one eye. Bilateral blindness was defined as a corrected visual acuity of $3 / 60$ or below in both eyes [8]. In most cases the cause of blindness was a single disorder. When there was more than one pathology in a patient, the $\mathrm{WHO}$ recommendation was adhered to: namely the most avoidable or preventable pathology was chosen as the cause of blindness or, alternatively, the cause that led to the last event rendering the individual sightless [2]. This principle was also adhered to while classifying the causes of blindness in unilateral cases when multiple causes were present in one eye. After establishing the diagnosis, medicines or glasses were prescribed as appropriate.

\section{Analysis}

Data were entered into Excel 2003 programme and analysed. The chi-squared test was used to compare the proportions in the community and hospital studies.

\section{Results}

The community study included 707 individuals: 256 (36.2\%) males and 451 females (63.8\%), a male:female ratio of $0.57: 1$. The hospital study was of 1320 individuals: 806 males (61.1\%) and 514 females (38.9\%), a male to female ratio of $1.57: 1$. The difference in the proportion of the sexes sampled was significant in both groups $(P<0.001)$. 
Table 1 shows the rate of bilateral and unilateral blindness for males and females in the community and hospital samples. In the community study the prevalence of bilateral blindness (best corrected visual acuity $<3 / 60$ in the better eye) was $7.9 \%$ (56 patients) and the main causes were cataract $(71.4 \%)$ and ARMD (14.3\%) (Table 2). The prevalence of unilateral blindness in the community study was $8.6 \%$ (61 patients) (Table 1) and the leading causes were cataract (62.3\%) and corneal opacities (9.8\%) (Table 2).

In the hospital study $26.5 \%$ (350 patients) were bilaterally blind and the main causes were cataract (47.7\%), glaucoma (11.4\%), ARMD (9.7\%), diabetic retinopathy $(9.4 \%)$, uncorrected aphakia $(6.3 \%)$ and corneal opacities (5.4\%). The rate of unilateral blindness was $9.0 \%$ (119 patients) and the leading causes were cataract $(27.7 \%)$, glaucoma (13.4\%), trauma-related ocular complications (11.8\%) and corneal opacities (11.8\%).

\section{Discussion}

The prevalence and causes of blindness have so far not been published from a community-based study in Yemen, but several hospital-based studies about the causes of blindness and visual impairment in adults and children have been published recently $[3,5,6]$. Reports showed that the prevalence of blindness in Yemen was around 1.0\%-2.0\% $[6,9]$. In our community-based study the prevalence of blindness in the age group $50+$ years was found to be $7.9 \%$. A nationwide rapid assessment should be carried out to estimate the prevalence of avoidable blindness in the community in all ages in Yemen.

The proportion of females examined in the community study was $63.8 \%$ versus $36.2 \%$. The difference could be explained by sampling bias as more males to females refused the examination. It is also likely that the population of rural areas is skewed as there is a higher rate of internal and external migration of males to other parts of the country or abroad. In contrast, in the hospital study the proportion of females was $38.9 \%$ and of males was $61.1 \%$. The high male:female ratio in the hospital-based study can be explained by the higher rate of men seeking medical advice in major cities and the difficulty in access to medical care for women.

Throughout the world $64 \%$ of the people who are blind are females. This may be because women live longer than men and are at greater risk of blindness from age-related causes - some blinding conditions such as trachoma and cataract are more likely to affect women than men - and because women and girls do not have easy access to eye care services $[9,10]$.

In previous hospital-based studies in Yemen the most common causes of blindness, in decreasing order, were cataract, glaucoma, diabetic retinopathy, ARMD and corneal opacities $[3,5]$. Cataract was the major cause of both bilateral and unilateral blindness in both our community and hospital samples. The prevalence of cataract bilateral blindness in the rural community area was $71.4 \%$ versus $47.7 \%$ in the city hospital sample.

Glaucoma was found to be the second major cause of bilateral (11.4\%) and unilateral (13.4\%) blindness in the hospital-based study, while in the community-based study, where glaucoma was defined as $\mathrm{C} / \mathrm{D}$ ratio $>0.5$ and intraocular pressure $>21 \mathrm{mmHg}$, only 1 case was found in the unilateral blindness group. Glaucoma patients who visit hospitals may be detected earlier because of better facilities such as applanation tonometry, visual field assessment, gonioscopy and dilated fundoscopy. In the community-based study most of these facilities were not available. This is a drawback of a community-based study.

ARMD is becoming more prevalent in the developed world due to the rising life expectancy of the populations. ARMD is also increasing in some developingcountriesfollowingimprovements in health care. Both our community and hospital-based studies showed a surprisingly high prevalence of ARMD as a cause of bilateral blindness (14.3\% and $9.6 \%$ respectively). This may be due to some special habits of the general Yemeni population in both sexes such

\begin{tabular}{|c|c|c|c|c|c|c|c|c|}
\hline \multirow[t]{2}{*}{ Type/Sex } & \multicolumn{3}{|c|}{ Community study } & \multicolumn{3}{|c|}{ Hospital study } & \multirow[t]{2}{*}{$x^{2}$-value } & \multirow[t]{2}{*}{$P$-value } \\
\hline & No. examined & No. affected & $\%$ affected & No. examined & No. affected & $\%$ affected & & \\
\hline \multicolumn{9}{|c|}{ Bilateral blindness } \\
\hline Male & 256 & 19 & 7.4 & 806 & 210 & 26.1 & 39.9 & $<0.001$ \\
\hline Female & 451 & 37 & 8.2 & 514 & 140 & 27.2 & 58.1 & $<0.001$ \\
\hline Total & 707 & 56 & 7.9 & 1320 & 350 & 26.5 & 99.4 & $<0.001$ \\
\hline \multicolumn{9}{|c|}{ Unilateral blindness } \\
\hline Male & 256 & 25 & 9.8 & 806 & 77 & 9.6 & 0.01 & 0.917 \\
\hline Female & 451 & 36 & 8.0 & 514 & 42 & 8.2 & 0.01 & 0.914 \\
\hline Total & 707 & 61 & 8.6 & 1320 & 119 & 9.0 & 0.09 & 0.769 \\
\hline
\end{tabular}




\begin{tabular}{|c|c|c|c|c|c|c|}
\hline \multirow[t]{2}{*}{ Type/Cause } & \multicolumn{2}{|c|}{ Community study $(n=56)$} & \multicolumn{2}{|c|}{ Hospital study $(n=350)$} & \multirow[t]{2}{*}{$x^{2}$-value } & \multirow[t]{2}{*}{$P$-value } \\
\hline & No. & $\%$ & No. & $\%$ & & \\
\hline \multicolumn{7}{|l|}{ Bilateral blindness } \\
\hline Cataract & 40 & 71.4 & 167 & 47.7 & 10.85 & $<0.001$ \\
\hline Glaucoma & 0 & 0.0 & 40 & 11.4 & - & - \\
\hline $\begin{array}{l}\text { Age-related macular } \\
\text { degeneration }\end{array}$ & 8 & 14.3 & 34 & 9.7 & 1.10 & 0.294 \\
\hline Corneal opacities & 1 & 1.8 & 19 & 5.4 & 1.34 & 0.247 \\
\hline Diabetic retinopathy & 0 & 0.0 & 33 & 9.4 & - & - \\
\hline Uncorrected aphakia & 1 & 1.8 & 22 & 6.3 & 1.82 & 0.177 \\
\hline Optic atrophy & 1 & 1.8 & 0 & 0.0 & - & - \\
\hline Other & 5 & 8.9 & 35 & 10.0 & 0.07 & 0.80 \\
\hline \multicolumn{7}{|l|}{ Unilateral blindness } \\
\hline Cataract & 38 & 62.3 & 33 & 27.7 & 19.20 & $<0.001$ \\
\hline Glaucoma & 1 & 1.6 & 16 & 13.4 & 6.10 & 0.014 \\
\hline $\begin{array}{l}\text { Age-related macular } \\
\text { degeneration }\end{array}$ & 2 & 3.3 & 1 & 0.8 & 1.51 & 0.219 \\
\hline Corneal opacities & 6 & 9.8 & 14 & 11.8 & 0.15 & 0.695 \\
\hline Diabetic retinopathy & 0 & 0.0 & 5 & 4.2 & - & - \\
\hline $\begin{array}{l}\text { Trauma-related ocular } \\
\text { complications }\end{array}$ & 2 & 3.3 & 14 & 11.8 & 3.33 & 0.068 \\
\hline Optic atrophy & 1 & 1.6 & 1 & 0.8 & 0.23 & 0.629 \\
\hline Other & 11 & 18.0 & 35 & 29.4 & 2.59 & 0.108 \\
\hline
\end{tabular}

as chewing qat leaves, which is usually accompanied by cigarettes or waterpipe smoking. Qat contains chemical substances such as cathinone, amphetamines, esters, citrals ethereal oils and tannins $[10,11]$. Cigarette smokers have 3 to 5 times higher risk of developing ARMD than nonsmokers [12]. ARMD is the leading cause of blindness in developed countries $[11,13]$ since nearly 2 out of 3 people will have developed early ARMD and 1 in 4 will have lost vision from ARMD [13,14].

Diabetic retinopathy was not detected in the community-based study as only a few cases had diabetes mellitus, while in the hospital-based study diabetic retinopathy was the fourth cause of bilateral blindness (9.4\%).

There was only 1 case of corneal opacities (1.8\%) in the communitybased study while in the hospital-based study it accounted for $5.4 \%$ of cases and this can be attributed to trauma, microbial corneal ulceration and use of traditional eye medicines.

Preventable causes of blindness, such as trauma-related complications, can be partially reduced at the primary levels of service delivery, whereas treatable causes, such as cataract, glaucoma, amblyopia and refractive errors, require specialized ophthalmology units, systems for early identifications and referrals, aswell asincreased public awareness of the possibility of treatment.

\section{Acknowledgements}

We extend out thanks to all the staff of Ibn Al-Haitham eye centre especially the manager Mr Abdallah Al-Ghubary. Also we appreciate the assistance of Dr Babar Qureshi, Director Academics of PICO, Pakistan for his supervision of the community-based study and to Dr Ahmed Mousa, Magrabi Hospital, Cairo for his help in statistical analysis.

\section{References}

1. Foster A, Gilbert C, Johnson G. Changing patterns in global blindness 1988-2008. Community Eye Health, 2008, 21(67):37-39.

2. Resnikoff $S$ et al. Global data on visual impairment in the year 2002. Bulletin of the World Health Organization, 2004, 82:844-851.
3. Resnikoff $\mathrm{S}$ et al. Global magnitude of visual impairment caused by uncorrected refractive errors in 2004. Bulletin of the World Health Organization, 2008, 86(1):63-70.

4. Family health survey 2003. Sana'a, Yemen, Ministry of Health, 2003. 
5. Al-Akily SA, Bamashmus MA. Causes of blindness among adult Yemenis: a hospital-based study. Middle East Journal of Oph thalmology, 2008, 15(1):3-6.

6. Bamashmus M, Al-Akily S. Pattern of childhood blindness and low vision in Yemen-hospital based study. Eastern Mediterranean Health Journal, 2010, 16(4):425-428.

7. Coding instructions for the WHO/PBL eye examination record (version III). Geneva, World Health Organization, 1988 (PBL/88.1).

8. International statistical classification of diseases and related health problems, tenth revision (ICD-10). Geneva, World Health Organization, 1992.

9. Resnikoff $\mathrm{S}$ et al. Global data on visual impairment in the year 2002. Bulletin of the World Health Organization, 2004, 82(11):844-851.
10. Courtright $P$, Lewallen $S$. Improving gender equity in eye care: advocating for the needs of women. Community Eye Health Journal, 2007, 20(64):68-69.

11. Feyissa AM, Kelly JP. A review of the neuropharmacological properties of khat. Progress in neuro-psychopharmacology \& biological psychiatry, 2008, 32(5):1147-1166.

12. Chan D. Cigarette smoking and age-related macular degeneration. Optometry and Vision Science, 1998, 75(7):476-484.

13. Bamashmus M, Matlhaga B, Dutton G. Causes of blindness and visual impairment in the West of Scotland. Eye, 2004, 18(3):257-261.

14. Taylor HR, Keeffe JE. World blindness: a 21st century perspective. British Journal of Ophthalmology, 2001, 85:261-266.

\section{Causes of blindness and visual impairment}

In spite of the progress made in surgical techniques in many countries during the last 10 years, cataract (47.9\%) remains the leading cause of visual impairment in all areas of the world, except for developed countries.

Other main causes of visual impairment in 2002 are glaucoma (12.3\%), age-related macular degeneration (AMD) (8.7\%), corneal opacities (5.1\%), diabetic retinopathy (4.8\%), childhood blindness (3.9\%), trachoma (3.6\%), and onchocerciasis $(0.8 \%)$. The causes of avoidable visual impairment worldwide are all the above except for AMD. In the least-developed countries, and in particular Sub-Saharan Africa, the causes of avoidable blindness are primarily, cataract (50\%), glaucoma (15\%), corneal opacities (10\%), trachoma (6.8\%), childhood blindness $(5.3 \%)$ and onchocerciasis (4\%).

Looking at the global distribution of avoidable blindness based on the population in each of the WHO regions, we see the following: South-East Asian 28\%, Western Pacific 26\%, African 16.6\%, Eastern Mediterranean 10\%, the American 9.6\%, and European 9.6\%.

Source: http://www.who.int/blindness/causes/en/ 